\title{
O DESENVOLVIMENTO MORAL NA EDUCAÇÃO FÍSICA: um estudo de revisão
}

\author{
Ana Maria Marcon' \\ Maria Luiza Rheingantz Becker ${ }^{2}$
}

\section{RESUMO}

Este artigo apresenta um levantamento das pesquisas publicadas em cinco periódicos da área de educação física, entre 2009 e 2013, referentes às concepções pedagógicas, formação de professores e prática docente para situar o desenvolvimento da moralidade na perspectiva desta disciplina. Evidencia-se que entre as possibilidades articuladas em diferentes discursos está o "como" e o "porquê"- utilizados como sinônimo de estabelecer objetivos e aprofundar as razões - tão importantes quanto o "saber fazer" que estão diretamente vinculados a formação moral.

Palavras-chave: Educação Física Escolar. Desenvolvimento Moral. Indisciplina.

1 Mestre em Educação. Professora da Universidade Federal do Rio Grande do Sul (UFRGS). Porto Alegre/Rio Grande do Sul, Brasil. E-mail: anamariamarcon@terra.com.br

2 Doutora em Educação. Professora da Faculdade de Educação da Universidade Federal do Rio Grande do Sul (UFRGS). Porto Alegre/Rio Grande do Sul, Brasil. E-mail: mlbecker@portoweb.com.br 
MORAL DEVELOPMENT IN THE PHYSICAL EDUCATION CLASSES: a review study

\section{ABSTRACT}

This article presents a survey of research published in five journals in the field of physical education between 2009 and 2013, relating to pedagogical conceptions, teacher training and teaching practice to situate the development of morality from the perspective of this discipline. It is evident that between the possibilities articulated in different speeches is the "how" and "why" - used as a synonym for set objectives and deepen the reasons - as important as "know-how" that are directly linked to moral education.

Keywords: Physical Education. Moral Development. Indiscipline.

\section{EL DESARROLLO MORAL EN LA EDUCACIÓN FÍSICA: UN ESTUDIO DE REVISIÓN}

\section{RESUMEN}

En este artículo se presenta un estudio de investigación publicado en cinco revistas de área de educación física entre 2009 y 2013, en referencia a los conceptos pedagógicos, formación de profesores y la enseñanza práctica de situar el desarrollo de la moral en el contexto de esta disciplina. Es evidente que entre las posibilidades articulados en diferentes discursos es el "cómo" y "por qué" - usa como sinónimo de los objetivos fijados y profundizar las razones - tan importante como el "saber hacer" que están directamente relacionados con la educación moral.

Palabras claves: Educación Física en la Escuela. Desarrollo Moral. La Indisciplina. 


\section{INTRODUÇÃO}

O desenvolvimento moral é tema recorrente e atual em diferentes esferas, sejam elas públicas ou privadas e preocupam pais e educadores. Para La Taille (2006), a moral e a ética se confundem no senso comum, mas enquanto a primeira se direciona ao fenômeno social, a segunda se vincula a reflexão filosófica. Na escola, o processo de educação moral está preso a um conjunto de regras diretamente relacionadas à disciplina, como se bastasse a memorização dos valores, sem a preocupação de saber como a criança constrói suas exigências morais. Souza, Queiroz e Menandro (2010) relatam que a literatura e as políticas públicas da área enfatizam a participação dos jovens nesta construção, no entanto afirmam que apesar deste reconhecimento as relações com as regras escolares continuam marcadas pelo tradicionalismo, como mostra o estudo de Souza e Placco (2005) que cita que as professoras, em caso de conflitos, orientam os alunos a "pararem as brigas e discussões", sem explorarem as possibilidades de reflexão sobre os desentendimentos. A

No centro da discussão sobre a responsabilidade da escola e da família, pergunta-se qual é a possibilidade da disciplina de Educação Física para responder a esta demanda. Os Parâmetros Curriculares Nacionais citam que devido à intensa mobilização afetiva das aulas, o caráter ético dos alunos se manifesta, proporcionando uma possibilidade de reflexão sobre valores (BRASIL, 1998). Está é a ideia do construtivismo, que entende que o desenvolvimento da moralidade é uma construção do sujeito em constante interação com o meio, diferente da abordagem da escola tradicional que atribui "a consciência moral a uma interiorização [...] seja por meio de identificações seja por meio de prêmios e castigos" (DELLAZZANA-ZANON, 2013, p.242).

As pesquisas realizadas por Piaget, expostas no livro O Juízo Moral da Criança (1994), compõem uma das abordagens utilizadas para estudar o desenvolvimento moral e têm o mérito de ressaltar o papel da consciência e das trocas sociais. Assim, de acordo com esta perspectiva, as relações sociais propiciadas nas aulas de educação física são fundamentais para que a criança se desenvolva moralmente. Neste sentido, a prática do jogo e do esporte nas aulas, isto é, apenas o fazer, não é suficiente, pois equivaleria a utilizar-se de métodos fundamentados na transmissão do gesto correto através da repetição, mais do que na reinvenção ou construção das regras e valores pelo aluno.

Apoiada na perspectiva piagetiana, esta investigação objetivou identificar a produção científica acerca do desenvolvimento moral na área da Educação Física , entre os anos de 2009 e 2013.

Partiu-se da ideia de que os periódicos arbitrados constituem-se um material qualificado, produzidos mediante critérios de rigor e fidedignidade.

O período de busca se refere aos cinco anos anteriores a elaboração desta revisão que compõe a dissertação de mestrado apresentada em 2015. A coleta se orientou para encontrar respostas para as seguintes questões: o desenvolvimento moral é ou pode vir a ser uma possibilidade no contexto das aulas de educação física; a dimensão moral é uma competência trabalhada no âmbito escolar; e por fim, os cursos de formação provêm uma fundamentação teórica relativa ao desenvolvimento moral? 


\section{O levantamento das pesquisas}

O levantamento seguiu os seguintes critérios: artigos publicados entre os anos de 2009 e 2013; nas seguintes revistas: Movimento; Motriz; Revista Brasileira de Ciências do Esporte; Revista de Educação Física e Desporto; e Pensar a Prática. A escolha de tais revistas deve-se porque, no ano realização da revisão, os presentes periódicos brasileiros eram as revistas que estavam entre os extratos mais altos do Qualis Capes, ou seja, entre A2 e B2.

No âmbito dos 1215 artigos encontrados, estabeleceram-se classes para responder as perguntas efetuadas na introdução deste artigo: títulos e resumos pertinentes aos temas concepções pedagógicas da educação física, prática docente e formação de professores. A classe concepção pedagógica compreende as tendências e abordagens da educação física na escola e no meio acadêmico, podendo-se observar se o desenvolvimento moral é ou pode vir a ser uma possibilidade neste contexto. O tema prática docente procura verificar se a dimensão moral é uma competência trabalhada no âmbito escolar. Por fim, a formação de professores foi pesquisada para verificar se os cursos de formação provêm uma fundamentação teórica relativa ao desenvolvimento moral. Através desse processo, restaram 50 artigos. Após a leitura, foram eliminados aqueles que não fossem artigos completos e não contemplassem o universo da escola. Após este critério de exclusão, restaram 23 artigos. Dois trabalhos foram acrescentados porque fazem um levantamento dos assuntos abordados nos periódicos da área. Assim, criou-se a classe Produção de Periódicos na Ed. Física.

Quadro 1 - Artigos da Revista Brasileira de Educação Física e Esporte

\begin{tabular}{|c|c|c|}
\hline Título & Autor & Referências \\
\hline $\begin{array}{l}\text { A educação física escolar e o projeto político } \\
\text { pedagógico: um processo de construção } \\
\text { coletiva a partir da pesquisa-ação. }\end{array}$ & Venâncio; Darido & v. 26, n. 1,2012 \\
\hline $\begin{array}{l}\text { Critérios para a implementação de } \\
\text { práticas pedagógicas na formação inicial } \\
\text { em educação física e implicações no } \\
\text { conhecimento pedagógico do conteúdo dos } \\
\text { futuros professores }\end{array}$ & $\begin{array}{l}\text { Marcon; Graça; } \\
\text { Nascimento }\end{array}$ & v. 25, n. 3,2011 \\
\hline $\begin{array}{l}\text { Tendências atuais da pesquisa brasileira em } \\
\text { educação física. Parte 2: a heterogeneidade } \\
\text { epistemológica nos programas de pós- } \\
\text { graduação. }\end{array}$ & Rosa; Leta & v. 25, n. 1,2011 \\
\hline $\begin{array}{l}\text { O jogo como precursor de valores no } \\
\text { contexto escolar }\end{array}$ & Sena, Lima & v. 23, n. 2,2009 \\
\hline Interação social em aulas de educação física. & $\begin{array}{l}\text { Rocha; Winterstein; } \\
\text { Amaral }\end{array}$ & v. 23, n. 3,2009 \\
\hline
\end{tabular}

Fonte: Dados da pesquisa. 
Quadro 2 - Artigos da Revista Movimento

\begin{tabular}{|l|c|c|}
\hline Título & Autor & Referências \\
\hline $\begin{array}{l}\text { A produção acadêmica sobre conteúdos } \\
\text { de ensino na educação física escolar }\end{array}$ & $\begin{array}{c}\text { Matos; Schneider; Mello; } \\
\text { Ferreira Neto; Santos }\end{array}$ & v. 19, n. 2, 2013 \\
\hline $\begin{array}{l}\text { Distanciamentos e aproximações entre } \\
\text { a educação física escolar e as propostas } \\
\text { pedagógicas críticas: o caso da teoria } \\
\text { crítico-emancipatória e didática } \\
\text { comunicativa }\end{array}$ & Morschbache; Marques & v. 19, n. 2, 2013 \\
\hline $\begin{array}{l}\text { Escola e formação para a cidadania: qual } \\
\text { o papel da educação física? }\end{array}$ & Ferreira, Castellani Filho & v. 18, n. 4, 2012 \\
\hline $\begin{array}{l}\text { Alternativas existem! Análise da } \\
\text { produção científica em dois periódicos } \\
\text { brasileiros sobre a docência na } \\
\text { educação física }\end{array}$ & Neira & v. 18, n. 1, 2012 \\
\hline $\begin{array}{l}\text { As práticas de desinvestimento } \\
\text { pedagógico na educação física escolar }\end{array}$ & $\begin{array}{c}\text { Machado; Bracht; Faria; } \\
\text { Almeida }\end{array}$ & v. 16, n. 2, 2010 \\
\hline $\begin{array}{l}\text { Dez anos de parâmetros curriculares } \\
\text { nacionais: a prática da educação física } \\
\text { na visão dos seus atores }\end{array}$ & \begin{tabular}{l} 
Gramorelli; Neira \\
\hline $\begin{array}{l}\text { Licenciatura em educação física: } \\
\text { concepções a partir da vivência } \\
\text { experienciada dos professores do ensino } \\
\text { superior em seu percurso formativo }\end{array}$
\end{tabular}$\quad \begin{array}{l}\text { Krüger; Krug } \\
\text { v.15, n.4 (2009) }\end{array}$ \\
\hline
\end{tabular}

Fonte: Dados da pesquisa.

Quadro 3 - Artigos da Revista Pensar a Prática

\begin{tabular}{|l|c|c|}
\hline Título & Autor & Referências \\
\hline $\begin{array}{l}\text { A prática docente do professor de } \\
\text { educação física escolar e a formação de } \\
\text { alunos crítico-reflexivos }\end{array}$ & Ilha; Krug & v. 16, n. 1, 2013 \\
\hline $\begin{array}{l}\text { Um diálogo com diferentes "formas-de- } \\
\text { ser" da educação física contemporânea } \\
\text { - duas teses (não) conclusivas... }\end{array}$ & $\begin{array}{c}\text { Rezer; Nascimento; } \\
\text { Fensterseifer }\end{array}$ & v. 14, n. 2, 2011 \\
\hline $\begin{array}{l}\text { O referencial curricular da educação } \\
\text { física do estado do Rio Grande do Sul: } \\
\text { uma análise qualitativa de conteúdo }\end{array}$ & $\begin{array}{l}\text { Martiny; Florêncio; } \\
\text { Gomes-da-Silva }\end{array}$ & v. 14, n. 1, 2011 \\
\hline
\end{tabular}

Fonte: Dados da pesquisa. 
Quadro 4 - Artigos da Revista Motriz

\begin{tabular}{|l|c|c|}
\hline Título & Autor & Referências \\
\hline $\begin{array}{l}\text { O estilo motivacional de professores de } \\
\text { Educação Física. }\end{array}$ & $\begin{array}{c}\text { Minelli; Nascimento; } \\
\text { Vieira; Barbosa-Rinaldi }\end{array}$ & v. 16, n. 3, 2010 \\
\hline $\begin{array}{l}\text { Competências do professor de educação } \\
\text { física e formação profissional }\end{array}$ & Correia; Ferraz & v. 16, n. 2, 2010 \\
\hline Educação Física como Linguagem. & Duarte & v. 16, n. 2, 2010 \\
\hline $\begin{array}{l}\text { O significado das aulas de Educação Física } \\
\text { para adolescentes. }\end{array}$ & Cruz; Fiamenghi Junior & v. 16, n. 2, 2010 \\
\hline $\begin{array}{l}\text { Educação física na década da educação para } \\
\text { o desenvolvimento sustentável }\end{array}$ & Osborne; Batista & v. 16, n. 1, 2010 \\
\hline $\begin{array}{l}\text { Educação Física e conteúdos trabalhados nas } \\
\text { séries iniciais do ensino fundamental }\end{array}$ & Silva; Dagostin; Nunes & v. 15, n. 3, 2009 \\
\hline $\begin{array}{l}\text { A educação física no ensino médio: saberes } \\
\text { necessários sob a ótica docente }\end{array}$ & Miranda; Lara; Rinaldi & v. 15, n. 3, 2009 \\
\hline $\begin{array}{l}\text { Caracterização dos modelos de estruturação } \\
\text { das aulas de educação física }\end{array}$ & Resende; Soares; Moura. & v. 15, n.1, 2009 \\
\hline $\begin{array}{l}\text { Formação acadêmica em educação física: } \\
\text { perfis profissionais, objetivos e fluxos } \\
\text { curriculares. }\end{array}$ & Hunger; Rossi & v. 16, n.1, 2010 \\
\hline
\end{tabular}

Fonte: Dados da pesquisa.

Quadro 5 - Artigos da Revista Brasileira de Ciências do Esporte

\begin{tabular}{|l|c|c|}
\hline Título & Autor & Referências \\
\hline $\begin{array}{l}\text { O papel da formação inicial no processo de } \\
\text { constituição da identidade profissional de } \\
\text { professores de educação física }\end{array}$ & Gariglio & v.32, n. 2-4, 2010 \\
\hline
\end{tabular}

Fonte: Dados da pesquisa.

Tabela 1 - Classes para análise dos periódicos.

$\begin{array}{rc}\text { Produção de Periódicos na Ed. Física } & 02 \\ \text { Formação do Professor } & 06 \\ \text { Concepções Pedagógicas } & 06 \\ \text { Prática Docente } & 11\end{array}$

Fonte: Dados da pesquisa.

Na classe Produção de Periódicos na Educação Física, temos os seguintes artigos: A Produção Acadêmica sobre Conteúdos de Ensino na Educação Física Escolar (MATOS et al., 2013) e; Alternativas existem! Análise da produção científica em dois periódicos 
brasileiros sobre a docência na Educação Física (NEIRA, 2012). Os textos revelam que, no período analisado, o desenvolvimento moral não foi um dos assuntos levantados nas pesquisas. Apesar de existir uma ideia sobre a necessidade de debater sobre outros conteúdos de ensino, vê-se que a perspectiva moral não é citada como uma possibilidade a ser considerada, como em Matos et al. (2013), contudo, em Neira (2012), encontramos a sugestão de tratar a ética como um tema transversal.

Na classe Formação do Professor, encontramos seis artigos, entre os quais: Licenciatura em Educação Física: concepções a partir da vivência experienciada dos professores do ensino superior em seu percurso formativo (KRÜGER; KRUG, 2009); Tendências Atuais da Pesquisa Brasileira em Educação Física. Parte 2: a heterogeneidade epistemológica nos programas de pós-graduação (ROSA; LETA, 2011); Competências do Professor de Educação Física e Formação Profissional (CORREIA; FERRAZ, 2010); Formação Acadêmica em Educação Física: perfis profissionais, objetivos e fluxos curriculares (HUNGER; ROSSI, 2010); Critérios para a Implementação de Práticas Pedagógicas na Formação Inicial em Educação Física e Implicações no Conhecimento Pedagógico do Conteúdo dos Futuros Professores (MARCON; GRAÇA; NASCIMENTO, 2011) e; O Papel da Formação Inicial no Processo de Constituição da Identidade Profissional de Professores de Educação Física (GARIGLIO, 2010).

Nos artigos de Correia e Ferraz (2010) e Cariglio (2010) encontramos a importância desta voltada para os valores éticos. Neste caminho, Rosa e Leta (2011) percebem um crescimento da pesquisa dirigida para as ciências humanas, assim como Hunger e Rossi (2010) citam a criação de novas disciplinas voltadas para pensamentos e ações reflexivas. Kruger e Krug (2009) contribuem com esta ideia ao afirmar que a formação deve ir além da aptidão física, da esportivização técnica e mecanicista. Marcon, Graça e Nascimento (2011) não abordam a moral.

Os seis artigos mencionados revelam uma preocupação crescente com a necessidade de implementação de diferentes modalidades de práticas pedagógicas com a finalidade de propiciar o abandono da mera transmissão de conhecimentos e a promoção da compreensão de valores e atitudes; antevendo com isto, uma maior possibilidade de reflexão, que proporcionaria uma visão crítica e contextualizada, ou seja, de autonomia moral e intelectual.

No sentido da implementação de diferentes práticas pedagógicas, pode-se inserir a proposta do desenvolvimento moral. Como concebido na teoria piagetiana, o desenvolvimento moral entende uma construção que precisa de um conhecimento específico. Conforme Neira (2012, p. 242):

O conhecimento específico se refere aos conteúdos que o professor ensina. É preciso que o docente tenha uma compreensão mínima e básica daquilo que vai ser ensinado, além de ter um bom conhecimento das possibilidades representacionais desses conteúdos.

Desta forma, trabalhar em prol do desenvolvimento moral significa entender a forma como o processo ocorre, isto é, a compreensão de valores e atitudes envolve uma 
estrutura de funcionamento que precisa de um conhecimento específico sobre os mecanismos que a regem.

Na classe concepções pedagógicas, seguem-se os seguintes artigos: Distanciamentos e Aproximações entre a Educação Física Escolar e as Propostas Pedagógicas Críticas: o caso da teoria crítico-emancipatória e didática comunicativa (MORSCHBACHER; MARQUES, 2013); Dez Anos de Parâmetros Curriculares Nacionais: a prática da educação física na visão dos seus atores (GRAMORELLI; NEIRA, 2009); Um Diálogo com Diferentes "Formas-de-Ser" da Educação Física Contemporânea: duas teses (não) conclusivas... (REZER; NASCIMENTO; FENSTERSEIFER, 2011); O Referencial Curricular da Educação Física do Estado do Rio Grande do Sul: uma análise qualitativa de conteúdo (MARTINY et al., 2011); Educação Física como Linguagem (DUARTE, 2010) e; Educação Física na Década da Educação para o Desenvolvimento Sustentável (OSBORNE; BATISTA, 2010).

As seis publicações apresentam caminhos variados que levam a "diferentes educações físicas", como citado por Rezer, Nascimento e Fensterseifer (2011), para a construção de um aluno crítico e reflexivo. Duarte (2010) aborda, a este respeito, a influência positiva da inserção da educação física na área das linguagens. Osborne e Batista (2010) propõem uma reflexão através da educação para o desenvolvimento sustentável. É importante citar que este é o único texto pesquisado em que há uma citação referente a Jean Piaget. O texto de Morschbacher e Marques (2013) e os artigos referentes aos Parâmetros Curriculares Nacionais (GRAMORELLI; NEIRA, 2009) e ao Referencial Curricular do Rio Grande do Sul (MARTINY et al., 2011) enfocam a construção de uma postura crítica através de "manifestações corporais provindas das práticas sociais".

Estes artigos mostram possibilidades de superação dos modelos tradicionais de ensino que baseiam-se no modelo heterônomo de atuação do professor, pautados na repetição e na memorização. Como visto, as abordagens preconizam um fazer crítico, ou seja uma postura renovada do professor condizente com uma concepção construtivista do conhecimento, que criam condições favoráveis para a inserção intencional do desenvolvimento moral na prática pedagógica.

Na classe Prática Pedagógica, encontram-se os artigos: A Educação Física no Ensino Médio: saberes necessários sob a ótica docente (MIRANDA; LARA; RINALDI, 2009); Caracterização dos Modelos de Estruturação das Aulas de Educação Física (RESENDE; SOARES; MOURA, 2009); A Educação Física Escolar e o Projeto Político Pedagógico: um processo de construção coletiva a partir da pesquisa-ação (VENÂNCIO; DARIDO, 2012); O Jogo como Precursor de Valores no Contexto Escolar (ROCHA; WINTERSTEIN; AMARAL, 2009); Interação Social em Aulas de Educação Física (SENA; LIMA, 2009); Escola e Formação para a Cidadania: qual o papel da educação física? (FERREIRA; CASTELLANI FILHO, 2012); As Práticas de Desinvestimento Pedagógico na Educação Física Escolar (MACHADO et al., 2010); A Prática Docente do Professor de Educação Física Escolar e a Formação de Alunos Crítico-Reflexivos (ILHA; KRUG, 2013); O Estilo Motivacional de Professores de Educação Física (MINELLI et al., 2010) e; O Significado das Aulas de Educação Física para Adolescentes (CRUZ; FIAMENGHI JUNIOR, 2010); Educação Física e Conteúdos Trabalhados nas Séries Iniciais do Ensino Fundamental (SILVA, DAGOSTIN; NUNES, 2009). 
Ao analisar o material voltado para a prática docente, que compõe a maioria dos artigos pesquisados, isto é, 11 artigos dos 25 analisados, há várias abordagens que trazem em comum a ideia da contextualização histórica, cultural e social da área, como em Miranda, Lara e Rinaldi (2009), Resende, Soares e Moura (2009), Venâncio e Darido (2012) e Ferreira e Castellani Filho (2012).

A ausência desta proposição pode levar ao desinvestimento da disciplina na escola, segundo Machado et al. (2010). Ilha e Krug (2013) corroboram com esta ideia ao afirmar que os professores não sabem como desenvolver o ensino críticoreflexivo e que, apesar da ampliação do debate sobre a educação física, desde a década de 1980, muitas localidades no país ainda priorizam o conteúdo esporte (SILVA, DAGOSTIN; NUNES, 2009). Nos artigos de Rocha, Winterstein e Amaral (2009) e Sena e Lima (2009) encontramos que o jogo e as interações sociais promovem possibilidades de reflexão, além de desenvolver valores morais e éticos (CRUZ; FIAMENGHI JUNIOR, 2010) para evitar a pressão dos grupos sociais. Minelli et al. (2010) citam também que o estilo motivacional altamente promotor de autonomia contribui para o desenvolvimento de comportamentos intrinsecamente motivados.

A partir do conjunto dos artigos analisados nesta classe pode-se supor que apesar das abordagens da disciplina de educação física entenderem a importância da reflexão, os professores não sabem como fazê-lo, seja por lacunas na formação ou por realizarem sequências pedagógicas independentes de qualquer concepção. Infere-se que sem proporcionar momentos em que os alunos possam refletir e criar soluções, os professores agem de forma coercitiva que não contribui para a construção da moralidade.

A teoria piagetiana define estágios para o desenvolvimento moral: a anomia, fase na qual as crianças não seguem regras coletivas, a heteronomia, originada nas relações de coação - modelo seguido pela escola tradicional - na qual a obediência se faz sem a reflexão e a autonomia, construída pelas relações de cooperação. Ressalta-se que as relações sociais favorecem a cooperação. Ao cooperar, o indivíduo precisa trocar pontos de vista, o que o faz situar suas ideias em relação a outras. Isto nada mais é do que refletir! De maneira simplificada, fazer um ensino reflexivo é dar voz aos alunos quando expõem seus pontos de vista ao procurarem soluções aos problemas propostos.

\section{CONSIDERAÇÕES FINAIS}

A teoria piagetiana é um referencial teórico assentado em um autor pouco explorado no campo da educação física. No entanto, traz contribuições que merecem ser analisadas no âmbito da prática escolar um vez que pauta o desenvolvimento, seja intelectual ou moral, nas trocas sociais.

Entende-se, através das leituras dos investigadores, que a educação física busca encontrar justificativas que a sustentem como disciplina. Entre as possibilidades articuladas em diferentes discursos está o "como" e o "porquê" - vinculados diretamente a ética e a moral - tão importantes quanto o "saber fazer". Muitos autores citam a teoria crítico-superadora 
como uma tendência que tem dirigido as propostas pedagógicas da área (MORSCHBACHER; MARQUES, 2013; FERREIRA; CASTELLANI FILHO, 2012). Neste caminho, vê-se que a teoria piagetiana - que entende que o desenvolvimento da inteligência, da afetividade, da socialização e da moralidade ocorre de forma solidária e complementar, frutos da maturação biológica, do meio, da experiência e da interação destes fatores que Piaget chamou de equilibração - pode contribuir para a busca de um ensino reflexivo e consequentemente de melhor qualidade da vida moral do homem. Neste sentido, o desenvolvimento moral pode ser uma proposta intencional nas aulas de educação física.

Enfatiza-se que para uma pessoa contextualizar histórica, cultural e socialmente o meio em que vive e agir com espírito crítico, precisa atingir um desenvolvimento cognitivo que lhe possibilite efetuar estas análises. Vê-se que o material pesquisado aponta para a necessidade de reflexão e a falta de uma fundamentação teórica que leve o professor a compreender como sua atuação pode contribuir para o processo de construção moral dos alunos. Pode-se inferir que o conhecimento do processo de construção da moralidade faz parte de uma das lacunas citadas na formação dos professores, que se manifesta na afirmação de que os mesmos não sabem como realizar um ensino reflexivo (ILHA; KRUG, 2013).

Não se espera que a educação física seja suficiente para cumprir com as demandas referentes ao desenvolvimento moral. Entretanto, pode-se concluir a partir do levantamento feito que a educação física inclui e propicia situações interpessoais e pedagógicas carregadas de sentido moral e ético. O professor consciente dessas relações se sentirá responsável por oportunizar uma educação moral.

Isto significa reconhecer a importância de desenvolver mais pesquisas sobre as possibilidades de construção da moralidade no fazer pedagógico da disciplina de educação física para que crianças e jovens tenham iniciativa de elaborar propostas de ação interpessoal e levá-las a níveis de complexidade (moral e intelectual) crescente, com compromisso com o que creem. Um suporte para referenciar essa criação de novas formas de condutas, no campo psicológico e epistemológico, pode ser encontrado na teorização piagetiana sobre o processo de construção de juízos morais e do agir consciente.

\section{REFERÊNCIAS}

BRASIL. Ministério da Educação. Parâmetros Curriculares Nacionais: Educação Física. Brasília: MEC/SEF, 1998.

CARIGLIO, J. A. O papel da formação inicial no processo de constituição da identidade profissional de professores de educação física. Revista Brasileira de Ciências do Esporte, Florianópolis, v. 32, n. 2-4, p. 11-28, dez. 2010.

CORREIA, R. N. P.; FERRAZ, O. L. Competências do professor de educação física e formação profissional. Motriz - Revista de Educação Física, Rio Claro, v. 16, n. 2, p. 281-291, abr./jun. 2010.

CRUZ, E. O.; FIAMENGHI JUNIOR, G. A. O significado das aulas de educação física para adolescentes. Motriz - Revista de Educação Física, Rio Claro, v. 16, n. 2, p. 425-431, abr./jun. 2010. 
DELLAZZANA-ZANON, L. L. et al. Pesquisas sobre desenvolvimento moral: contribuições da psicologia brasileira. Psico, Porto Alegre, PUCRS, v. 44, n. 3, pp. 342-351, jul./ set. 2013.

DUARTE, L. Educação física como linguagem. Motriz - Revista de Educação Física, Rio Claro, v. 16, n. 2, p. 31-39, abr./jun. 2010.

FERREIRA, F. C.; CASTELLANI FILHO, L. Escola e formação para a cidadania: qual o papel da educação física? Movimento, Porto Alegre, v. 18, n. 4, p. 135-154, out./dez. 2012.

GARIGLIO, J. A.O papel da formação inicial no processo de constituição da identidade profissional de professores de educação física. Revista Brasileira de Ciências do Esporte, Florianópolis, v. 32, n. 2-4, p. 11-28, dez. 2010.

GRAMORELLI, L. C.; NEIRA, M. G. Dez Anos de Parâmetros Curriculares Nacionais: a prática da educação física na visão dos seus autores. Movimento, Porto Alegre, v. 15, n. 4, p. 107-126, out./dez. 2009.

HUNGER, D, A. C. F.; ROSSI, F. Formação acadêmica em educação física: perfis profissionais, objetivos e fluxos curriculares. Motriz - Revista de Educação Física, Rio Claro, v. 16, n. 1, p. 170-180, jan./mar. 2010.

ILHA, F. R. S.; KRUG, H. N. A prática docente do professor de educação física escolar e a formação de alunos crítico-reflexivos. Revista Pensar a Prática, Goiânia, v. 16, n. 1, p. 197-210, jan./abr. 2013.

KRÜGER, L. G.; KRUG, H. N. Licenciatura em educação física: concepções a partir da vivência experienciada dos professores. Movimento, Porto Alegre, v. 15, n. 1, p. 5170, jan./mar. 2009.

LA TAILLE, Yves de. Moral e ética: dimensões intelectuais e afetivas. Porto Alegre: Artmed, 2006.

MACHADO, T. et al. As práticas de desinvestimento pedagógico na Educação Física escolar. Movimento, Porto Alegre, v. 16, n. 02, p. 129-147, abr./jun., 2010.

MARCON, D.; GRAÇA, A. B. S.; NASCIMENTO, J. V. Critérios para a implementação de práticas pedagógicas na formação inicial em educação física e implicações no conhecimento pedagógico do conteúdo dos futuros professores. Rev. Bras. Educ. Fís. Esporte. São Paulo, v. 25, n. 3, p. 497-511, jul./set. 2011.

MARTINY, L. E.. et al. O Referencial Curricular da Educação Física do estado do Rio Grande do Sul: uma análise qualitativa de conteúdo. Revista Pensar a Prática, Goiânia, v. 14, n. 1, p. 1-14, jan./abr. 2011.

MATOS, J. C. et al. A produção acadêmica sobre conteúdos de ensino na educação física escolar. Movimento, Porto Alegre, v. 19, n. 2, p. 123-148, abr./jun. 2013.

MINELLI, D. S. et al. O estilo motivacional de professores de educação física. Motriz Revista de Educação Física, Rio Claro, v. 16, n. 3, p.598-609, jul./set. 2010.

MIRANDA, A.C. M.; LARA, L. M.; RINALDI, I. P. B. A educação física no ensino médio: saberes necessários sob a ótica docente. Motriz - Revista de Educação Física, Rio Claro, v. 15, n. 3, p. 621-630, jul./set. 2009.

MORSCHBACHER, M.; MARQUES, C. L. S. Distanciamentos e aproximações entre a educação física escolar e as propostas pedagógicas críticas: o caso da teoria crítico- 
julho/2017

emancipatória e didática comunicativa. Movimento, Porto Alegre, v. 19, n. 2, p. 149166, abr./jun. 2013.

NEIRA, M. G. Alternativas existem! Análise da produção científica em dois periódicos brasileiros sobre a docência na educação física. Movimento, Porto Alegre, v. 18, n. 1, p. 241-257, jan./mar. 2012.

OSBORNE, R.; BATISTA, W. A. educação física na década da educação para o desenvolvimento sustentável. Motriz - Revista de Educação Física, Rio Claro, v. 16, n. 1, p.28-36, jan./mar. 2010.

PIAGET, J. O Juízo Moral na Criança. São Paulo: Summus, 1994.

RESENDE, H, G.; SOARES, A. J. G.; MOURA, D. L. Caracterização dos modelos de Estruturação das aulas de Educação Física. Motriz - Revista de Educação Física, Rio Claro, v. 15, n. 1, p.37-49, jan./mar. 2009.

REZER, R.; NASCIMENTO, J.; FENSTERSEIFER, P. Um diálogo com diferentes "formasde-ser" da educação física contemporânea: duas teses (não) conclusivas... Pensar a Prática, Goiânia, v. 14, n. 2, p. 1-14, maio/ago. 2011.

ROCHA, B.; WINTERSTEIN, P. J.; AMARAL, S. C. F. Interação social em aulas de educação física. Rev. Bras. Educ. Fís. Esporte. São Paulo, v. 23, n. 3, p. 235-245, jul./set. 2009. ROSA, S.; LETA, J. Tendências atuais da pesquisa brasileira em educação física Parte 2: a heterogeneidade epistemológica nos programas de pós-graduação. Rev. Bras. Educ. Fís. Esporte, São Paulo, v. 25, n. 1, p. 7-18, jan./mar. 2011.

SENA, S.; LIMA, J. M. O jogo como precursor de valores no contexto escolar. Rev. Bras. Educ. Fís. Esporte, São Paulo, v. 23, n. 3, p. 247-262, jul/set. 2009.

SILVA, J. V. P.; DAGOSTIN, K. U. D.; NUNES, P. R. M. Educação física e conteúdos trabalhados nas séries iniciais do ensino fundamental. Motriz - Revista de Educação Física, Rio Claro, v. 15, n. 3, p. 592-599, jul./set. 2009.

SOUZA, V. M. T.; PLACCO, V. M. N. S. A interação na escola e seus significados e sentidos na formação de valores. Psicologia da Educação, São Paulo, v. 21, p. 53-77, $2^{\circ}$ sem. 2005.

SOUZA, L. G. S.; QUEIROZ, S. S.; MENANDRO, M. C. S. E quando os estudantes pedem mais disciplina? Estudo de caso e reflexões sobre autonomia e vida escolar. Psicologia: Ciência e Profissão, Brasília, v. 30, n. 3, p. 524-539, set. 2010.

VENÂNCIO, L.; DARIDO, S. C. A Educação Física Escolar e o Projeto Político Pedagógico: um processo de construção coletiva a partir da pesquisa-ação. Rev. Bras. Educ. Fís. Esporte, São Paulo, v. 26, n. 1, jan./mar. 2012.

Recebido em: abril/2016 Aprovado em: dezembro/2016 